\title{
Effects of risedronate on fracture risk in postmenopausal women with osteopenia
}

\author{
E. S. Siris • J. A. Simon • I. P. Barton • \\ M. R. McClung • A. Grauer
}

Received: 23 April 2007 / Accepted: 27 September 2007 / Published online: 30 October 2007

(C) International Osteoporosis Foundation and National Osteoporosis Foundation 2007

\begin{abstract}
Summary This posthoc analysis of four trials studied the efficacy of risedronate to reduce fragility fractures in postmenopausal women with osteopenia (i.e., T-scores between -1 and -2.5$)$. Risedronate reduced the fracture risk by $73 \%(p=0.023)$ in this population of women with low femoral neck bone mass and no prevalent vertebral fractures. Introduction Low bone mass represents an increasing health risk and burden. Half of fragility fractures occur in osteopenic women underscoring the need for treatments reducing fracture risk. This analysis reports the effect of risedronate to reduce fragility fracture risk in osteopenic women without prevalent vertebral fractures.

Methods Postmenopausal women with osteopenia, defined as femoral neck T-score between -1 and -2.5 by DXA and no prevalent vertebral fractures, were identified from four controlled randomized trials (BMD Multinational, BMD North America, VERT Multinational and VERT North America). The risk reduction for fragility fractures in
\end{abstract}

\section{E. S. Siris $(\square)$}

Toni Stabile Osteoporosis Center,

Columbia University Medical Center,

180 Fort Washington Avenue,

New York, NY 10032, USA

e-mail: es27@columbia.edu

\section{J. A. Simon}

George Washington University,

Washington, DC, USA

\section{P. Barton · A. Grauer}

Procter \& Gamble Pharmaceuticals,

Cincinnati, OH, USA

M. R. McClung

Oregon Osteoporosis Center,

Portland, OR, USA patients receiving $5 \mathrm{mg}$ risedronate daily for 1.5 to 3 years compared to placebo was assessed. An additional sensitivity analysis excluded patients who were osteopenic at the femoral neck but had a BMD lower than $-2.5 \mathrm{SD}$ at the lumbar spine.

Results Six hundred and twenty postmenopausal women with osteopenia were included, receiving either placebo $(n=309)$ or risedronate $5 \mathrm{mg}(\mathrm{n}=311)$. Risedronate reduced the risk of fragility fractures by $73 \%$ over 3 years versus placebo $(\mathrm{p}=0.023)$; cumulative fragility fracture incidence was $6.9 \%$ in placebo-treated versus $2.2 \%$ in risedronatetreated patients. The magnitude of the effect was similar in the sensitivity analysis subset.

Conclusion Risedronate significantly reduced the risk of fragility fractures in postmenopausal women with osteopenia (femoral neck T-score between -1 and $-2.5 \mathrm{SD}$ ) and no prevalent vertebral fractures.

Keywords Bisphosphonates · Fragility fracture · Nonvertebral fracture · Osteopenia $\cdot$ Risedronate . Vertebral fracture

\section{Introduction}

Low bone mass, defined by bone mineral density (BMD) values in the osteopenic range, can progress to osteoporosis if left untreated. Additionally, it has recently become apparent that osteopenia is a significant risk factor for fragility fractures in older women. Studies using peripheral and central dual x-ray absorptiometry (DXA) to determine BMD have demonstrated that approximately half of all fragility fractures occur in women with osteopenic BMD [1-5]. As the number of women with low bone mass is projected to increase to 30.4 million in 2020 , this condition 
presents a significant medical problem and socioeconomic burden [6]. Prevalence projections for 2020 are significantly higher than current rates $(21.8$ million women in 2002) due to expected population growth and aging [7].

Based on BMD testing, the World Health Organization (WHO) clinically defines women with osteopenia as those whose BMD T-score is between 1 and 2.5 standard deviations (SD) below the mean of peak bone mass in healthy, young normal women (i.e., -1 to $-2.5 \mathrm{SD}$ ); women with osteoporosis include all those at or below $-2.5 \mathrm{SD}$ [8-10]. However, these definitions provide a diagnostic categorization of low bone mass rather than an intervention threshold that could be used to determine the need for the initiation of treatment to reduce fracture risk. Physicians are often faced with making treatment decisions for postmenopausal patients with $\mathrm{T}$ scores in the osteopenic range, increasing the need for evidence-based guidance to define populations at high risk for fracture [11].

The National Osteoporosis Foundation (NOF) currently recommends an algorithm for initiation of therapy to reduce the risk of fracture [12]. According to this algorithm, treatment should be initiated in osteopenic women with Tscores $<-2.0$ by central DXA with no risk factors and in women with T-scores $<-1.5$ by central DXA with one or more risk factors $[9,10,12,13]$.

Despite the existence of NOF guidelines for the treatment of postmenopausal women with low bone mass, limited clinical data exist as a foundation for supporting therapeutic intervention in this group. Although it is possible to identify osteopenic women at higher or lower short-term risk for fracture [11], there are limited data regarding the effectiveness of osteoporosis treatments to lower fracture risk in these women. This is in part due to the inherent difficulty in collecting fracture data from osteoporosis trials, which usually exclude women with higher T-scores who may fall into the osteopenic range. The assembly of large data sets is, therefore, difficult and the feasibility of prospective osteopenic fracture trials is limited due the lower incidence of fracture in this population compared with patients with osteoporosis [14]. The use of post hoc analysis is one way to overcome some of these obstacles and provide information about effectiveness of treatments in non-osteoporotic populations.

We have analyzed data from four Phase III risedronate trials: BMD Multinational (BMD-MN) [15], BMD-North America (NA) [16], Vertebral Efficacy with Risedronate Therapy-Multinational (VERT-MN) [17], and Vertebral Efficacy with Risedronate Therapy-North America (VERTNA) [18] in which efficacy and safety of risedronate in the prevention and treatment of postmenopausal osteoporosis have been demonstrated. Using data only from osteopenic women included in these trials, this study evaluated the effect of risedronate in reducing the risk of fragility fractures in women with femoral neck T-scores in the osteopenic range and without prevalent vertebral fracture.

\section{Methods}

Study design and patients

This retrospective analysis included the subsets of postmenopausal women with osteopenia in four risedronate placebo-controlled osteoporosis trials [15-18] of 1.5 to 3 years' duration.

Patients included in the current analysis were postmenopausal women who had no radiographic vertebral fractures at baseline and had a femoral neck T-score between -1 and $-2.5 \mathrm{SD}$ as measured by DXA (NHANES III). These selection criteria were similar to those in previously published studies looking at similar populations $[19,20]$.

Although inclusion criteria for the VERT trials required patients to have prevalent vertebral fractures, re-adjudication conducted by central radiographic assessment after enrollment showed that between $10 \%$ and $15 \%$ of enrolled patients had no prevalent vertebral fracture and could, therefore, be included in the present study. Our analysis was based on BMD assessment at the femoral neck rather than the lumbar spine, due to its greater reliability and predictive value and wide acceptance internationally for clinical diagnosis $[2,13]$.

Patients treated with estrogen and estrogen-related drugs within 3 months of study entry or for more than 1 month within 6 months of study entry were excluded from the original studies. All patients received $1,000 \mathrm{mg}$ calcium and, if needed, $500 \mathrm{IU}$ vitamin D daily.

Adverse event information was collected at the study visits made every 3 months during the trials. The investigator recorded adverse events reported by the patients, as well as adverse events observed on examination of the patient.

\section{Identification of fragility fractures}

Fragility fractures were defined as a composite of a patient's incident morphometric vertebral and osteoporosis-related nonvertebral fractures (i.e., six fracture types including clavicle, humerus, wrist, pelvis, hip or leg fractures). This endpoint was chosen to include all radiographically confirmed fractures.

With respect to the nonvertebral fractures, the selection of the nonvertebral fracture sites (clavicle, humerus, wrist, pelvis, hip or leg) followed the pre-specified definition of osteoporosis-related nonvertebral fractures of the risedronate trial program, which has been reported in all regulatory and previous scientific reports from this program. All osteoporosis related nonvertebral fractures required radiographic confirmation. The term "leg" fracture as used in the risedronate 
trials is a summary term, including the treatment emergent adverse event codes for fibula, tibia, subtrochanteric fracture, and leg, but not those for ankle or distal tibia fracture, the terms by which ankle fractures are usually reported.

\section{Statistical analyses}

The primary analysis focused on investigating the effect of risedronate to reduce fragility fractures (both vertebral and nonvertebral) in postmenopausal women who had no radiographic vertebral fractures at baseline and were considered osteopenic based on a femoral neck T-score ranging between $-1 \mathrm{SD}$ and $-2.5 \mathrm{SD}$.

For consistency with previous risedronate studies, the statistical analysis used time-to-first-event methodology. Cumulative fracture incidence was estimated using the Kaplan-Meier method, and a Cox proportional hazards regression model was used to estimate the relative fracture risk reduction, via the hazard ratio (HR), between the risedronate $5 \mathrm{mg}$ and placebo groups. The regression model was stratified for each trial to allow for separate underlying hazard functions. In order to determine the acceptability of combining data from all trials, potential heterogeneity assessments were performed using the Cox regression model to assess the trial-by-treatment, age-by-treatment and baseline femoral neck BMD-by-treatment interactions. Fracture efficacy for nonvertebral osteoporosis-related fractures and new vertebral fractures were also investigated. A sensitivity analysis was conducted to investigate whether the exclusion of patients with lumbar spine T-score $<-2.5$ SD would influence the outcome of the primary analyses. As the inclusion criteria for the primary analysis were low bone mass at the femoral neck (BMD T-score between -1 and $-2.5 \mathrm{SD}$ ), we felt it was important to test whether the exclusion of patients with an osteoporotic BMD at another site would significantly affect the results.

Adverse events, serious adverse events, withdrawals, deaths, and upper gastrointestinal adverse events were summarized by treatment group. Differences in the proportions of patients between the treatment groups were tested using the Fisher's exact test.

\section{Results}

Patients

A total of 620 postmenopausal women met the criteria for low bone mass and were included in the current analysis. Patients received either placebo $(n=309)$ or risedronate $5 \mathrm{mg}(\mathrm{n}=311)$. Baseline characteristics were similar for each patient group (Table 1). The mean age was 64 years for both groups and mean baseline femoral neck T-scores were -1.84 in the placebo group and -1.85 in the risedronate group, respectively.

Potential heterogeneity assessments revealed that there were no significant interactions for trial-by-treatment $(p=$ $0.495)$, age-by-treatment $(\mathrm{p}=0.981)$ or baseline femoral neck BMD-by-treatment $(\mathrm{p}=0.188)$

\section{Effect on fractures}

Risedronate treatment was found to significantly reduce the risk of combined morphometric vertebral and nonvertebral fractures by $73 \%$ in women with a femoral neck T-score between -1 and -2.5 and no prevalent vertebral fracture; $\mathrm{HR}=0.27,95 \% \mathrm{CI}=0.09-0.83, \mathrm{p}=0.023$ (Fig. 1). The cumulative fragility fracture incidence was $6.9 \%$ and $2.2 \%$ respectively for placebo and risedronate.

When separated according to nonvertebral and vertebral fractures, the cumulative nonvertebral fracture incidence was $5.4 \%$ and $0.4 \%$, respectively, for placebo and risedronate $(\mathrm{HR}=0.09,95 \% \mathrm{CI}=0.01-0.71 \quad(\mathrm{p}=0.022)$, and the cumulative vertebral fracture incidence was $4.2 \%$ and $1.8 \%$, respectively, for placebo and risedronate $(\mathrm{HR}=0.44,95 \%$ $\mathrm{CI}=0.11-1.78 \quad(\mathrm{p}=0.249)$.
Table 1 Baseline characteristics of patients with a femoral neck T-Score $\geq-2.5 \mathrm{SD}$ and $\leq-1$ SD without prevalent vertebral fractures

\footnotetext{
a Mean (standard deviation)

b Based on National Health and Nutrition Examination Survey III reference database
}

\begin{tabular}{|c|c|c|c|c|}
\hline & \multicolumn{2}{|l|}{ All patients } & \multicolumn{2}{|c|}{$\begin{array}{l}\text { Excluding lumbar spine } \\
\text { T-score }<-2.5 \mathrm{SD}\end{array}$} \\
\hline & $\begin{array}{l}\text { Placebon } \\
\mathrm{n}=309\end{array}$ & $\begin{array}{l}\text { Risedronate } \\
5 \mathrm{mg} \mathrm{n}=311\end{array}$ & $\begin{array}{l}\text { Placebon } \\
\mathrm{n}=146\end{array}$ & $\begin{array}{l}\text { Risedronate } \\
5 \mathrm{mg} \mathrm{n}=147\end{array}$ \\
\hline Age (years) ${ }^{\mathrm{a}}$ & $64(7.5)$ & $64(7.5)$ & $63(8.3)$ & $65(7.0)$ \\
\hline Femoral neck T-score ${ }^{\mathrm{a}, \mathrm{b}}$ & $-1.84(0.396)$ & $-1.85(0.406)$ & $-1.77(0.418)$ & $-1.76(0.398)$ \\
\hline Height $(\mathrm{cm})^{\mathrm{a}}$ & $159.8(6.92)$ & $159.8(6.05)$ & $160.6(6.14)$ & $160.4(6.32)$ \\
\hline Weight $(\mathrm{kg})^{\mathrm{a}}$ & $65.9(11.92)$ & $66.8(11.19)$ & $69.8(12.91)$ & $69.6(12.27)$ \\
\hline BMI $\left(\mathrm{kg} / \mathrm{m}^{2}\right)^{\mathrm{a}}$ & $25.9(4.54)$ & $26.2(4.36)$ & $27.2(5.1)$ & $27.1(4.78)$ \\
\hline $\begin{array}{l}\text { Patients with prevalent } \\
\text { OP-related nonvertebral fractures }\end{array}$ & $56(18 \%)$ & $59(19 \%)$ & $34(23 \%)$ & $31(21 \%)$ \\
\hline
\end{tabular}




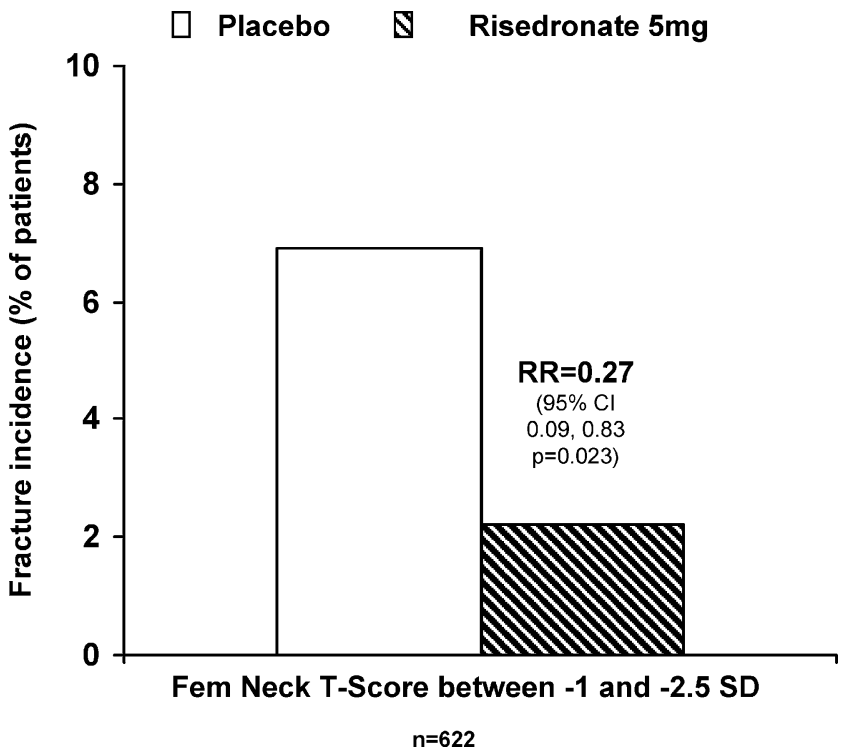

Fig. 1 Reduction of fragility fracture risk in patients with femoral neck T-score between -1 and $-2.5 \mathrm{SD}$ and no prevalent vertebral fractures

\section{Sensitivity analyses}

When patients with baseline LS spine T-scores below $-2.5 \mathrm{SD}$ were excluded, results consistent with those from the primary analysis population were observed, although the reduced sample size widened the confidence intervals and led to a loss of statistical significance. For the 293 patients who had both femoral neck and LS spine T-scores between -2.5 and -1 SD, the hazard ratio for fragility fractures was $0.22 \quad(95 \%$ $\mathrm{CI}=0.03-2.02, \mathrm{p}=0.182$ ), a magnitude of effect similar to that in the primary analysis population.

\section{Safety}

In the subgroup investigated for this analysis, no statistically significant differences in adverse events between the risedronate treated and the placebo group were recorded during the trial (Table 2). The observation in the subgroup analysis reported here is consistent with the findings in the overall population of the original trials [15-18].

\section{Discussion}

Osteopenia is common in postmenopausal women and contributes to the increased risk of fracture in this population. There is a need for clinical data examining both fracture risk in women with T-scores in the osteopenic range and the evidence for an effect of treatment on reducing that risk. Data from the National Osteoporosis Risk Assessment (NORA) study reported that more than half of women experiencing self-reported fractures of the hip, vertebrae, rib and wrist/forearm at one year fell into the osteopenic category based on peripheral BMD T-scores between -1 and -2.5 [21]. Results from the present study show that risedronate treatment significantly reduced the overall risk of fragility fractures by $73 \%$ over 3 years in patients with a femoral neck T-score between -1 and -2.5 and no prevalent vertebral fracture. A similar reduction in risk - that did not reach statistical significance due to low numbers - was observed when patients with lumbar spine T-scores below -2.5 were excluded from the analysis.

Previous studies in women with osteoporosis have shown that risedronate reduces the risk of morphometric vertebral fractures by up to $65 \%$ in the first year of treatment $[17,18]$, with significant reductions in clinical vertebral and nonvertebral fractures as early as 6 months [22, 23]. Moreover, a study in osteoporotic women without prevalent fracture demonstrated that treatment with risedronate reduced the risk of first vertebral fracture by $75 \%$ (i.e., a relative risk of 0.25 ) [24].

Previously reported studies have examined the efficacy of alendronate [20, 25] and raloxifene [19] on fracture risk reduction in osteopenic populations. A retrospective reanalysis of data from the Fracture Intervention Trial (FIT) showed a $60 \%$ reduction of vertebral fractures [RR 0.40 $(0.19-0.7695 \% \mathrm{CI})]$ in osteopenic women defined as having a femoral neck BMD T-score between -1.6 and -2.5 [20]. The overall analysis included patients with or without prevalent vertebral fractures, however, and since prevalent vertebral fractures are an important risk factor for further fractures and a criterion for severe osteoporosis $[8,13]$, classifying such women as osteopenic is subject to debate. When a subset of this population, those without
Table 2 Summary of adverse events (AEs) for patients with a femoral neck T-score $\geq-2.5$ $\mathrm{SD}$ and $\leq-1 \mathrm{SD}$ and no prevalent vertebral fractures (BMD and VERT Trials)

p-values were from Fisher's exact test.

UGI: upper gastrointestinal

\begin{tabular}{llll}
\hline \multirow{2}{*}{ Category } & \multicolumn{2}{l}{ Number of patients $(\%)$} & p-value \\
\cline { 2 - 3 } & Placebo $(\mathrm{n}=309)$ & Risedronate 5 mg $(\mathrm{n}=311)$ & \\
\hline AEs & $290(93.9 \%)$ & $293(94.2 \%)$ & 0.87 \\
Serious AEs & $40(12.9 \%)$ & $56(18.0 \%)$ & 0.10 \\
AEs associated with death & $2(0.6 \%)$ & $0(0.0 \%)$ & 0.25 \\
UGI AEs & $77(24.9 \%)$ & $81(26.0 \%)$ & 0.78 \\
Withdrawn due to AEs & $38(12.3 \%)$ & $26(8.4 \%)$ & 0.11 \\
\hline
\end{tabular}


prevalent fractures, was analyzed separately the results were similar, but did not reach statistical significance [RR $0.46(0.16-1.1795 \% \mathrm{CI})]$. Results in patients with both hip and spine BMD in the osteopenic range are not reported in this paper. A re-analysis of the Multiple Outcomes of Raloxifene Evaluation (MORE) study reported similar rates of vertebral fracture risk reduction in raloxifene-treated women with osteopenia - defined as a total hip T-score > -2.5 without a prevalent vertebral fracture - compared with those with osteoporosis at 3 years [19]. The relative risk reduction for vertebral fractures with raloxifene compared with placebo was $0.53(0.32-0.88,95 \% \mathrm{CI})$ in osteopenic women; the relative risk for clinical vertebral fractures in osteopenic women was $0.25(0.04-0.63)$. Information about reduction of nonvertebral fractures has not been provided in either the alendronate or raloxifene analyses. Conjugated equine estrogens significantly reduced the risk of clinical vertebral, hip and total fractures in postmenopausal women in the Women's Health Initiative, the vast majority of whom did not have bone density testing but who were not selected based on having diagnosed osteoporosis [26]. Finally, a study of women $\geq 75$ years of age in the UK reported that oral daily clodronate $800 \mathrm{mg}$ for 3 years reduced any clinical fracture by $20 \%$, but not hip fractures, in women unselected for having osteoporosis [27]. This reduction was independent of baseline BMD, but the number needed to treat was greater in the non-osteoporotic subjects.

The fracture benefit observed with risedronate in patients with low bone mass in our analysis may result in part from the effect of this compound on the preservation of bone microarchitecture. In previous studies of both early postmenopausal women and osteoporotic patients risedronate was observed to preserve trabecular architecture, including trabecular number, thickness and separation, compared to placebo [28, 29], which is likely to contribute to a maintenance of bone strength [30]. This beneficial effect on trabecular architecture has also been observed with long-term treatment with risedronate, as shown by recent data from a study in postmenopausal osteoporotic women [31]. Bone microarchitecture, assessed by three-dimensional micro-computed tomography, was maintained at similar levels over a fiveyear treatment period [31]. The sustained preservation of bone microarchitecture equates to a long-term beneficial effect on bone strength and may contribute to the decrease in fracture risk observed with risedronate treatment.

Limitations of the current study include the selection of initial populations in the VERT and BMD trials based on the presence of risk factors for osteoporosis (including low BMD and prevalent vertebral fractures). Because the original trials were designed to examine the efficacy of osteoporosis treatments in an osteoporotic population, rather than to determine representative incidence of fracture in a general osteopenic population, the data provided in the present analysis may reflect an overestimation of the fracture risk in the general postmenopausal population.

It is likely that in the relatively near future fracture risk assessment using a combination of femoral neck BMD, age, and other risk fractures will be utilized to determine absolute fracture risk and also serve as a basis for determining treatment intervention thresholds. In many older postmenopausal women, osteopenia will be an important risk factor for fracture, placing some of them at high absolute risk of a fracture event over a 10 year interval [32], and treatment with a pharmacologic agent will be indicated to lower risk. The data presented here demonstrate that in addition to the established efficacy in preventing fracture in osteoporotic women with or without prevalent fractures, risedronate significantly reduces the risk of fragility fractures in this population of postmenopausal women with osteopenic BMD values at the femoral neck and no prevalent vertebral fractures.

Acknowledgments Funding for this study was provided by the Alliance for Better Bone Health (Procter \& Gamble Pharmaceuticals, Cincinnati, OH, USA and sanofi-aventis, Paris, France).

The authors would like to thank Dr. Aijun Gao, COMPSYS, for the quality control of the statistical analyses.

\section{References}

1. Siris ES, Miller PD, Barrett-Connor E et al (2001) Identification and fracture outcomes of undiagnosed low bone mineral density in postmenopausal women: results from the National Osteoporosis Risk Assessment. JAMA 286:2815-2822

2. Schuit SC, van der Klift M, Weel AE et al (2004) Fracture incidence and association with bone mineral density in elderly men and women: the Rotterdam Study. Bone 34:195-202

3. Wainwright SA, Marshall LM, Ensrud KE et al (2005) Hip fracture in women without osteoporosis. J Clin Endocrinol Metab 90:2787-2793

4. Sornay-Rendu E, Munoz F, Garnero P et al (2005) Identification of osteopenic women at high risk of fracture: the OFELY study. J Bone Miner Res 20:1813-1819

5. Sanders KM, Nicholson GC, Watts JJ et al (2006) Half the burden of fragility fractures in the community occur in women without osteoporosis. When is fracture prevention cost-effective? Bone 38:694-700

6. America's bone health: The state of osteoporosis and low bone mass in our nation (2002) National Osteoporosis Foundation, Washington, DC

7. Bone Health and Osteoporosis (2004) U.S. Department of Health and Human Services, Office of the Surgeon General, Rockville, MD

8. Assessment of fracture risk and its application to screening for postmenopausal osteoporosis. Report of a WHO Study Group (1994) World Health Organ Tech Rep Ser 843:1-129

9. Prevention and Management of Osteoporosis (2003) Geneva: World Health Organization, Technical Report Series, Vol. 921

10. Guidelines for Preclinical Evaluation and Clinical Trials in Osteoporosis (1998) WHO Technical Bulletin: World Health Organization 
11. Miller PD, Barlas S, Brenneman SK et al (2004) An approach to identifying osteopenic women at increased short-term risk of fracture. Arch Intern Med 164:1113-1120

12. Physician's Guide to Prevention and Treatment of Osteoporosis (2003) National Osteoporosis Foundation, Washington, DC

13. Kanis JA (2002) Diagnosis of osteoporosis and assessment of fracture risk. Lancet 359:1929-1936

14. Kanis JA, Oden A, Johnell O et al (2002) Uncertain future of trials in osteoporosis. Osteoporos Int 13:443-449

15. Fogelman I, Ribot C, Smith R et al (2000) Risedronate reverses bone loss in postmenopausal women with low bone mass: results from a multinational, double-blind, placebo-controlled trial. BMD-MN Study Group. J Clin Endocrinol Metab 85:1895-1900

16. McClung MR, Bensen WG, Bolognese MA et al (1998) Risedronate increases bone mineral density at the hip, spine and radius in postmenopausal women with low bone mass. Osteoporos Int 8:111

17. Reginster J, Minne HW, Sorensen OH et al (2000) Randomized trial of the effects of risedronate on vertebral fractures in women with established postmenopausal osteoporosis. Vertebral Efficacy with Risedronate Therapy (VERT) Study Group. Osteoporos Int 11:83-91

18. Harris ST, Watts NB, Genant HK et al (1999) Effects of risedronate treatment on vertebral and nonvertebral fractures in women with postmenopausal osteoporosis: a randomized controlled trial. Vertebral Efficacy With Risedronate Therapy (VERT) Study Group. JAMA 282:1344-1352

19. Kanis JA, Johnell O, Black DM et al (2003) Effect of raloxifene on the risk of new vertebral fracture in postmenopausal women with osteopenia or osteoporosis: a reanalysis of the Multiple Outcomes of Raloxifene Evaluation trial. Bone 33:293-300

20. Quandt SA, Thompson DE, Schneider DL et al (2005) Effect of alendronate on vertebral fracture risk in women with bone mineral density T-score from -1.6 to -.2 .6 at the femoral neck: The Fracture intervention trial. Mayo Clin Proc 80:343-349

21. Siris ES, Chen YT, Abbott TA et al (2004) Bone mineral density thresholds for pharmacological intervention to prevent fractures. Arch Intern Med 164:1108-1112

22. Roux C, Seeman E, Eastell R et al (2004) Efficacy of risedronate on clinical vertebral fractures within six months. Curr Med Res Opin 20:433-439
23. Harrington JT, Ste-Marie LG, Brandi ML et al (2004) Risedronate rapidly reduces the risk for nonvertebral fractures in women with postmenopausal osteoporosis. Calcif Tissue Int 74:129-135

24. Heaney RP, Zizic TM, Fogelman I et al (2002) Risedronate reduces the risk of first vertebral fracture in osteoporotic women. Osteoporos Int 13:501-505

25. Black D, Thompson D, Quandt S et al (2002) Alendronate reduces risk of vertebral fracture in women with BMD t-scores above 2.5: results from the Fracture Intervention Trial (FIT). J Bone Miner Res 17:S474

26. Rossouw JE, Anderson GL, Prentice RL et al (2002) Risks and benefits of estrogen plus progestin in healthy postmenopausal women: principal results from the Women's Health Initiative randomized controlled trial. JAMA 288:321-333

27. McCloskey EV, Beneton M, Charlesworth D et al (2007) Clodronate reduces the incidence of fractures in communitydewlling elderly women unselected for osteoporosis: Results of a double-blind, placebo-controlled randomized study. J Bone Miner Res 22:135-141

28. Dufresne TE, Chmielewski PA, Manhart MD et al (2003) Risedronate preserves bone architecture in early postmenopausal women in 1 year as measured by three-dimensional microcomputed tomography. Calcif Tissue Int 73:423-432

29. Borah B, Dufresne TE, Chmielewski PA et al (2004) Risedronate preserves bone architecture in postmenopausal women with osteoporosis as measured by three-dimensional microcomputed tomography. Bone 34:736-746

30. Borah B, Dufresne TE, Chmielewski PA et al (2002) Risedronate preserves trabecular architecture and increases bone strength in vertebra of ovariectomized minipigs as measured by threedimensional microcomputed tomography. J Bone Miner Res 17:1139-1147

31. Borah B, Ritman EL, Dufresne TE et al (2004) Sustained effect of risedronate on trabecular architecture and mineralization over 5 years of treatment: triple biopsy studies by micro-CT. European Symposium on Calcified Tissues, Nice, France, June 5-9

32. Kanis JA, Johnell O, Oden A et al (2001) Ten year probabilities of osteoporotic fractures according to BMD and diagnostic thresholds. Osteoporosis Int 12:989-995 